\section{A rare case report: Acquired vulva lymphangioma in a young female post tubercular lymphadenitis}

\author{
Marissa Astari, Afif Nurul Hidayati \\ Department of Dermatology and \\ Venerology, School of Medicine, \\ Universitas Airlangga, Dr. Soetomo \\ General Hospital, Universitas Airlangga \\ Hospital Surabaya, Indonesia
}

\begin{abstract}
Lymphangioma are rare benign proliferations of the lymphatic system. Acquired lymphangioma circumscriptum of the vulva is a superficial lymphatic malformation, presenting as lymph-filled micro-to macroscopic vesicles. We describe a rare case of acquired vulva lymphangioma resulting from tubercular lymphadenitis. A 20-yearold female came to Dermatology and Venereology Outpatient Clinic of Dr. Soetomo General Hospital with chief complain there were multiple clusters vesicles on her genitalia since three months ago. The vesicles followed with discomfort and slightly itchy. There was a lymphedema on both of her inguinal since 5 years ago. She was diagnosed with tubercular lymphadenitis in 13 years old of age. No history of sexual transmitted disease. She had 5 times of cryotherapy and it nearly got remission.
\end{abstract}

\section{Introduction}

Lymphangioma is rare benign proliferations of the lymphatic system. It is either congenitally present at birth or develops in early childhood or acquired. Acquired lymphangioma circumscriptum of the vulva is a superficial lymphatic malformation, presenting as lymph-filled micro-to macroscopic vesicles. Vulvar involvement by lymphangioma is rare. ${ }^{1}$ It is often times disfiguring and can negatively affect one's quality of life duet o complications such as infection and pain, making it of high value to elucidate current treatment options for the condition. High recurrance rates and a risk of scarring make lymphangioma circumscriptum difficult to treat. $^{2}$ Several choices treat lymphangioma such as surgical excision, laser therapy, sclerotherapy, cryotherapy, radiotherapy, electrocautery, electrodessication, and more recently imiquiomod.

\section{Case Report}

A 20-year-old female came to the Dr. Soetomo General Hospital in Dermatology and Venereology Outpatient Clinic Department with chief complain there were multiple clusters vesicles that colourless until yellow-ish and release clear liquid on her genitalia since 3 months ago. The vesicles followed with discomfort and slightly itchy. There was a lymphedema on both of her inguinal since five years ago. She was diagnosed with Lymphadenitis TB when she was 13-years-old and already got six months of antituberculosis drugs. No history of sexual transmitted disease.

The histoplathology examination showed there were acanthosis, elongation of rete ridge, dilated lymph 1-2 lymphocite cells and the conclusion was as superficial lymphangioma. (Figures 1 and 2).

We treated the patient with five sessions of cryotherapy and it nearly got full remission. But a month after the last cryotherapy, she complained there were new vesicle appeared. (Figure 2).

\section{Discussion and Conclusions}

We present a case of acquired lymphangioma of the vulva post tubercular lymphadenitis. It is a rare case since not much reported. Peachey et al. distinguished two main forms of lymphangioma: localized and classic. ${ }^{3}$ It is most commonly accepted that lymphangioma are clinically and histologically develop in areas affected by obstruction or destruction of lymphatic drainage.

Vulva lymphangioma can be asymptomatic, pruritic, burning or painful. ${ }^{1}$ It is an unpleasent but benign condition. In our patient, there were discomfort and slightly itchy. Lumphangioma is characterized by
Correspondence: Afif Nurul Hidayati, Department of Dermatology and Venerology, School of Medicine, Universitas Airlangga, Dr. Soetomo General Hospital, Universitas Airlangga Hospital Surabaya, Indonesia. Tel.: +628123028024

E-mail: afif_nurulhidayati@fk.unair.ac.id

Key words: Vulva lymphangioma, Lymphangioma circumscriptum.

Contributions: The authors contributed equally.

Conflict of interests: The authors declare no potential conflict of interest.

Received for publication: 1 February 2019. Accepted for publication: 25 February 2019.

This work is licensed under a Creative Commons Attribution-NonCommercial 4.0 International License (CC BY-NC 4.0).

CCopyright M. Astari and A.N. Hidayati, 2019 Licensee PAGEPress, Italy

Dermatology Reports 2019; 11(s1):8093

doi:10.4081/dr.2019.8093

translucent vesicles, which may be scattered or grouped like frog-spawn. Rarely ther lesions can have a firm hyperkeratotic appeasrence. ${ }^{4,5}$

Acquired vulva lymphangioma could be attributed to many condition. These include congenital and acquired lymphedema associated with infections such as filariasis, sexually transmitted disease, tuberculosis, erysipelas, and lymphogranuloma venerum, Chron's disease, congenital dysplastic angiopathy, surgical or radiotherapic procedures, trauma, keloids, scleroderma, and lymphatic obstruction associated with neoplasia. ${ }^{6,7}$ In our patient, tubercular lymphadenitis coupled with scarring led to the obstruction of the vulval lymphatics resulting lymphangoma.
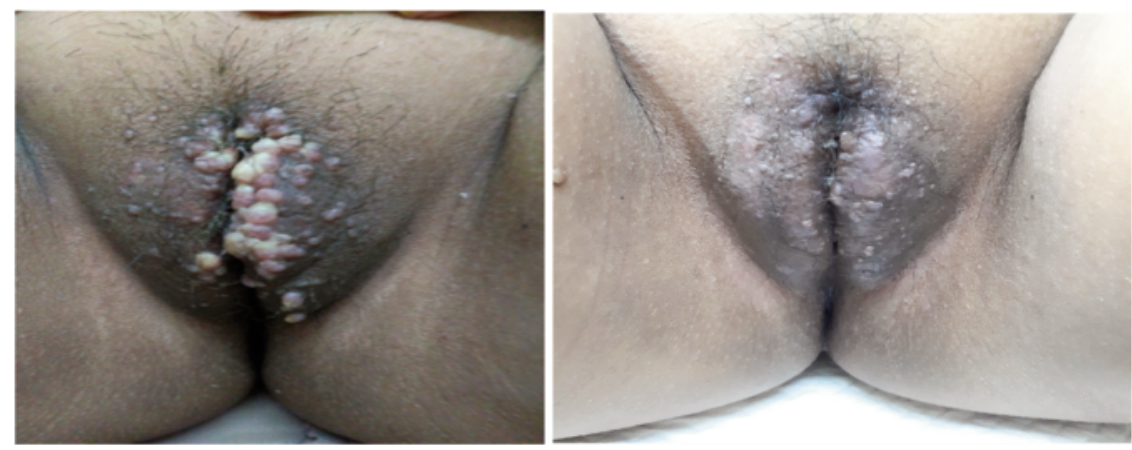

Figure 1. (A) Clinical Manifestation before treatment. Multiple clusters of colourless until yello-ish in genitalia region; (B) After 5 times of cryotherapy. The lesions nearly got full remission. 


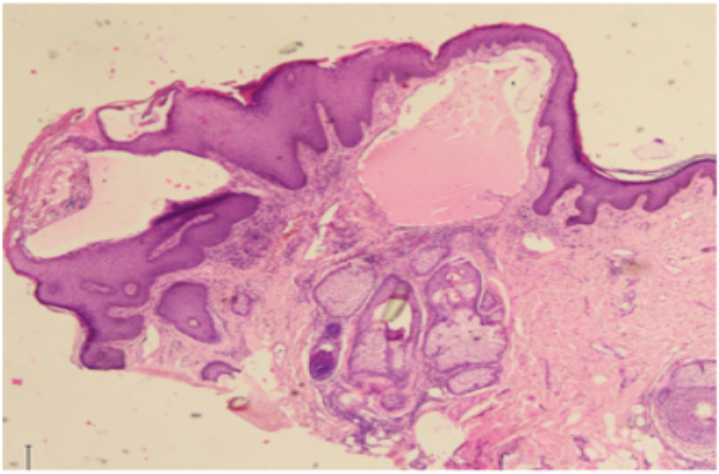

Figure 2. Result of histopathology examination: acanthosis, elongation of rete ridge, and dilated lymph 1-2 lymphocite cells.

Several choices treatments of lymphangioma such as surgical excision, laser therapy, sclerotherapy, cryotherapy, radiotherapy, electrocautery, electrodessication, and more recently imiquiomod.

Most of the therapeutic options facilitated clearence of lymphangioma circumscriptum with minimal adverse effects.(2) Karadeg et al. described regression of lymphangioma after five sessions at four-week intervals of PDL treatment combined with five sessions of double freeze-thaw cycles of cryotherapy at three week intervals with no recurrence after two years. Cryotherapy uses very low temperatures to cause vaso- constriction immediately followed by reactive vasodilatation resulting in cellular necrosis.(8) In our case, we did five sessions of cryotherapy only and it nearly remission.

Complications associated with vulva lymphangioma include cellulitis and psychosexual dysfucntion. ${ }^{8}$ Follow up of patients with lymphedema is recommended because the possibility of the complication and recurrances.

\section{References}

1. Meriem Amouri1, Abderrahmen
Masmoudi1, Sonia Boudaya1, Ali Amouri2, Issam Ben Ali2, Samir Bouassida1, Mohamed Guermazi2 HT. Acquired lymphangioma circumscriptum of the vulva. Dermatology Online J 13 10. 2007;

2. Perper M, Cervantes J, Eber AE, Hsu VM, Alharbi $\mathrm{M}$ et al. Lymphangioma Circumscriptum: Treatment Modalities for this Unyielding Condition. J Clin Investig Dermatol. 2017;5(1).

3. Peachey RD, Lim CC WI. Lymphangioma of the skin: a review of 65 cases. Br J Dermatol. 1970;83:51927.

4. A. Virgili MC. Lymphangioma and lymphangiectasis of the vulva. J Euro Acad DermatoloVenereol. 1997;8:229_ 32.

5. G. Gokdemir, I. Kivanc-Altunay Y. Acquired vulvar lymphangiomatosis after cancer therapy. Inter $\mathrm{J}$ Gynecol Obs. 2003;81:65-7.

6. Vlastos AT, Malpica A FM. Lymphangioma circumscriptum of the vulva: a review of the literature. Obs Gynecol. 2003;101:946-54.

7. B R. ymphangioma circumscriptum and keloids. Br J Dermatol. 1951;63:158-9.

8. Emer J, Gropper J, Gallitano S LJ. A case of lymphangioma circumscriptum seccesfully treated with electrodessication following failure of pulsed dye laser. dermatol Online J. 2013;19:2. 